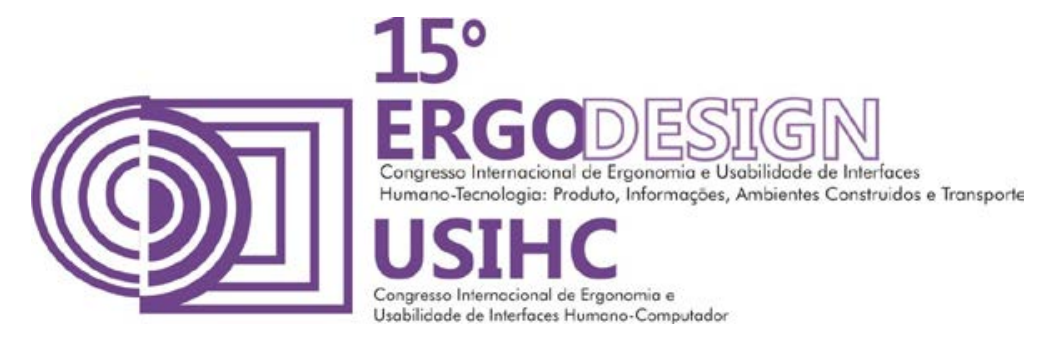

\title{
ANÁLISE DE OPINIÃO E ESTRATÉGIAS DE USO DE APLICATIVOS DE SMARTPHONE DURANTE A CONDUÇÃO
}

\section{ANALYSIS OF OPINION AND STRATEGIES OF USE OF SMARTPHONE APPLICATIONS WHILE DRIVING}

\author{
QUARESMA, Manuela (1); \\ GONÇALVES, Rafael (2) \\ RODRIGUES, Marcela (3)
}

(1) Laboratório de Ergodesign e Usabilidade de Interfaces da PUC-Rio (LEUI),

\author{
Doutora em Design \\ e-mail: mquaresma@puc-rio.br
}

(2) Laboratório de Ergodesign e Usabilidade de Interfaces da PUC-Rio (LEUI),

Bolsista de Iniciação Tecnológica FAPERJ

e-mail: rafaelcirinogoncalves@gmail.com

(3) Laboratório de Ergodesign e Usabilidade de Interfaces da PUC-Rio (LEUI),

Bolsista de Iniciação Tecnológica CNPq

e-mail: marcela.arodrig@gmail.com

\begin{abstract}
RESUMO
Este estudo teve como objetivo principal a criação de um panorama geral sobre as opiniões, estratégias de uso e comportamento do motorista no uso de smartphones durante a condução. Para a obtenção dos resultados, o estudo utilizou-se de um questionário veiculado por plataforma digital com uma abrangência de todo o território nacional. Os resultados apontam para uma desconsideração parcial de fatores relativos à segurança rodoviária em favor de uma maior praticidade do uso, sem medir necessariamente as implicações de tais atos.
\end{abstract}

Palavras-chave: comportamento do motorista, aplicativos, smartphone, distração do motorista, segurança rodoviária

\section{ABSTRACT}

This study aimed as it's main objective the creation of a prospect about the driver's behavior, opinion and interaction strategies with their smartphones while driving. To reach the purposed results, this study used a online survey with a nationwide range. The results pointed out for a certain driver's lack of care about safety matters in favor of use facilities, without consider the implications of this behavior.

Keywords: driver behavior, apps, smartphone, driver distraction, road safety 


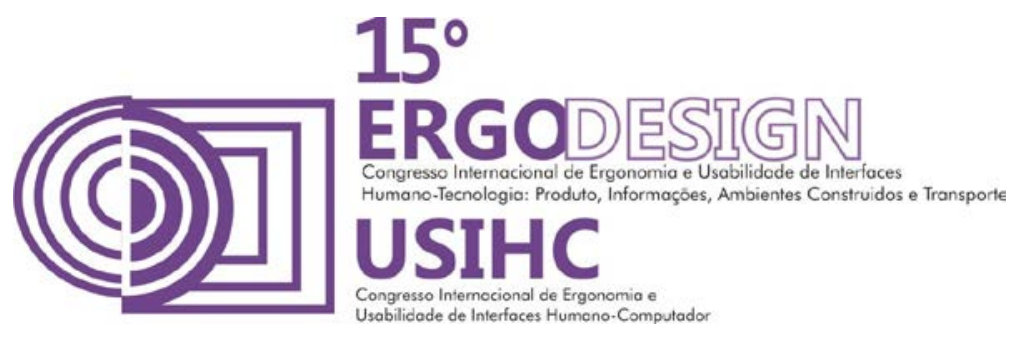

\section{INTRODUÇÃO}

O uso de smartphones vem aumentando cada vez mais e já faz parte do dia-a-dia de muitas pessoas, seja em casa, no trabalho e no deslocamento pela cidade. Com isso, o desenvolvimento de diversos aplicativos também é, consequentemente, acelerado para suprir as necessidades que os usuários encaram durante o dia, como por exemplo, obter informações de tráfego. Com a antena GPS acoplada ao smartphone, muitos aplicativos passaram a ser desenvolvidos para auxiliar os usuários e motoristas em seus deslocamentos.

Atualmente, existem vários aplicativos de smartphone para serem usados durante a condução de um automóvel, seja para guiar o motorista ao longo do caminho que ele deve percorrer, seja para dar informações sobre o tráfego, seja para avisar sobre os eventos que estão ocorrendo no trânsito (como acidentes, obras, etc.), e muitos outros serviços. É possível observar nas lojas de aplicativos que, a cada dia, novos aplicativos/serviços vêm sendo desenvolvidos para o uso em automóveis.

Os aplicativos de smartphone destinados para motoristas podem ser classificados e subdivididos em geral em 5 subcategorias: 1) Aplicativos de navegação GPS, projetados para traçar rotas e guiar os motoristas para diferentes destinos estabelecidos pelos mesmos (ex. Tomtom - figura 1, Sygic e iGo Primo); 2) Redes sociais para motoristas, aplicativos que utilizam a internet para criar uma rede colaborativa de compartilhamento de informações relativas ao trânsito (ex. Waze - figura 2, Trapster e Wabbers); 3) Sistemas de informação sobre o trânsito, destinados a fornecer informações relevantes dos mais diferentes tópicos relativos ao tráfego, como pontos de engarrafamento, blitz e acidentes e afins (ex. VaiRio - figura 3, iRadar e afins); 4) Trip computers, aplicativos com a função de fornecer informações relevantes sobre a própria condução e/ou o desempenho do carro, tal como velocidade média, consumo de combustível e aceleração do veículo (ex. Speedometer, Speed Tracker - figura 4, Car OBD); 5) Assistentes de condução, aplicativos que utiliza periféricos do aparelho (como câmera, acelerômetro e afins) para fornecer auxilio em tempo real, com alertas ou sugestões de manobra (ex. iOnRoad - figura 5, Safety Sight). Estes são apenas alguns exemplos dentro das categorias que existem hoje em dia, a tendência é que o número de aplicativos e de categorias cresça com o tempo, visto que, por exemplo, só a Apple App Store teve um crescimento de de $30 \%$ de 2013 a 2014 no número de aplicativos disponíveis para download, totalizando 1,3 milhão de aplicativos (Statista, 2015). 


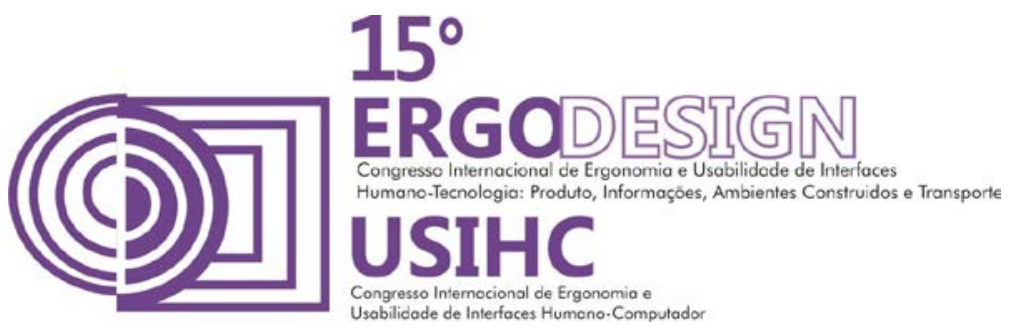

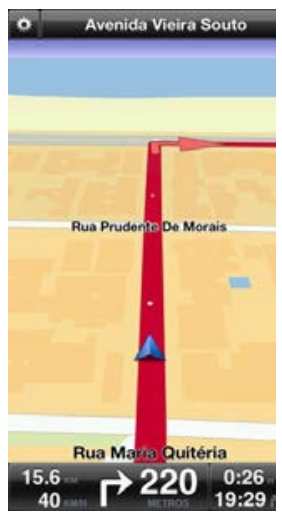

Figura 1 TomTom

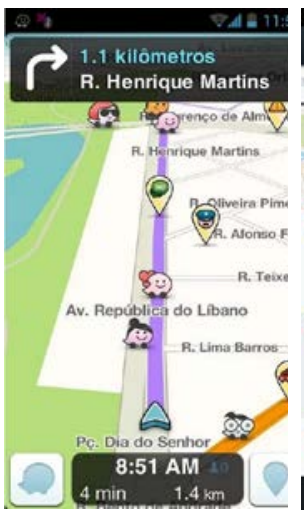

Figura 2 - Waze

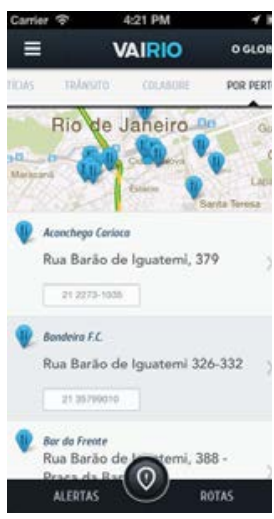

Figura 3 - Vai Rio

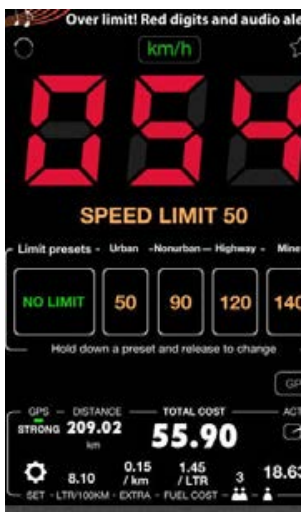

Figura 4 - Speed Tracker

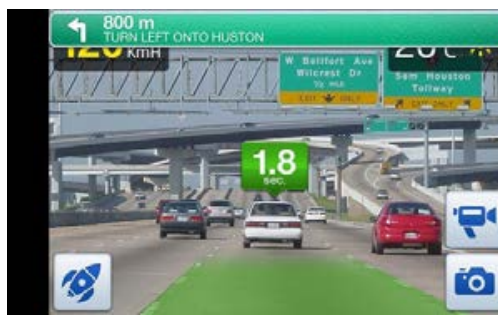

Figura 5 - iOnRoad

Devido a especificidade do seu contexto de uso, o desenvolvimento de aplicativos para uso em automóveis deve considerar uma série de questões singulares de crucial importância para a segurança rodoviária. Este fato é tão alarmante que em 2014 a National Highway Traffic Safety Administration (NHTSA, 2014) fez uma reunião pública com o objetivo de se estabelecer diretrizes de concepção para dispositivos móveis a serem utilizados durante a condução, levando em conta fatores relativos à segurança.

\section{PROBLEMA}

Como podem ser observadas nas interfaces desses aplicativos exemplificados e mesmo em outros disponíveis para motoristas, muitas das funções e soluções dadas aos sistemas não estão de acordo com o contexto da condução, seja pelo tamanho dos botões/alvos de toque, muito pequeno para o alcance devido a trepidação automóvel, quanto de informações muito pequenas para ser lidas (Quaresma e Gonçalves, 2013; 2014). Não só o tamanho reduzido das áreas de toque e das informações, mas também a falta de preocupação com questões de segurança, como a interrupção e retomada das tarefas, podem comprometer o desempenho do motorista. A interrupção e retomada de tarefas é fundamental para a boa interação com os aplicativos, uma vez que é extremamente perigoso desempenhar uma tarefa no aplicativo durante a condução de forma contínua, sem alternar a visão entre a via e a própria interface do aplicativo.

Além disso, outras questões parecem ser problemáticas nesses aplicativos, como a demanda visual necessária para a conclusão de tarefas devido a problemas de excesso de informação em tela e/ou na arquitetura de informação, traçando um longo percurso entre a tela inicial e o objetivo do usuário. Foram também encontrados problemas de entrada de dados, falta de padronização e compatibilidade em relação à expectativa do usuário e aos 


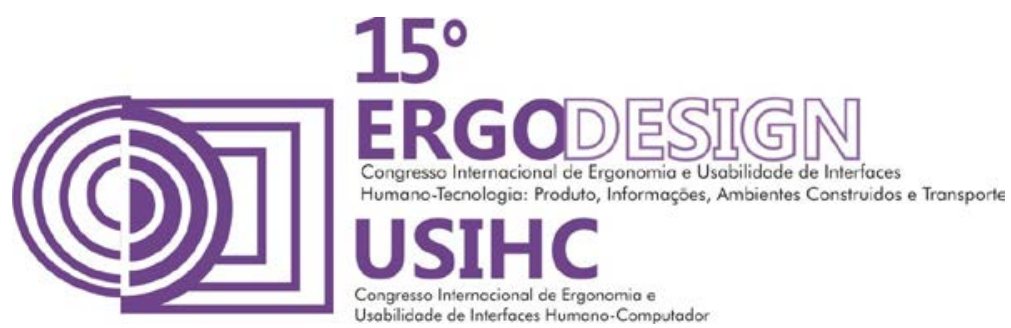

sistemas operacionais onde os aplicativos rodam. Todos esses problemas podem levar a potenciais distrações do motorista, prejudicando a segurança rodoviária (Quaresma, 2012).

Por serem portáteis, smartphones e seus aplicativos podem ser utilizados, em tese, em qualquer situação, logo, os aplicativos devem estar preparados para a interação nos mais diversos contextos de uso, considerando as peculiaridades de cada um (Wroblewsky, 2011; Clark, 2010). O órgão de regulamentação de trânsito dos Estados Unidos NHTSA (2014) afirma que para evitar a distração do motorista com dispositivos eletrônicos durante a condução, faz-se necessária a consideração de fatores específicos deste contexto (como o tempo de conclusão e interrupção da tarefa, assim como o modo de apresentação das informações) durante a concepção dos mesmos, o que nem sempre ocorre.

Dessa forma, é necessário o conhecimento do contexto em que o usuário utiliza o seu smartphone. Visto que não há um ambiente ideal para a realização da tarefa, é preciso entender como o ambiente externo influencia nessa interação, quais os hábitos e estratégia de uso de cada motorista, para que os aplicativos possam se adaptar melhor ao modelo mental do usuário, mitigando assim o risco em seu uso e otimizando a interação.

\section{METODOLOGIA}

Este estudo teve como principal objetivo identificar as necessidades, hábitos e estratégias dos motoristas no uso de aplicativos de smartphone durante a condução. Com estes dados, pretende-se levantar um panorama geral sobre o perfil do usuário motorista, colaborando assim para a concepção de produtos de melhor qualidade afetando indiretamente a segurança no trânsito.

Tendo em vista os objetivos acima, foram estabelecidas as seguintes perguntas de pesquisas, que serviram de norte para o desenvolvimento de um questionário:

- Como os motoristas utilizam seus smartphones durante a condução?

- Qual o tipo de informação eles procuram nos aplicativos?

- Qual a sua frequência de uso destes aplicativos?

- Qual a opinião dos motoristas quanto ao uso de aplicativos durante a condução e sobre a qualidade do design de suas interfaces?

Para responder estas questões foi aplicado um questionário online, com proposições/questões objetivas e algumas perguntas abertas. Optou-se pela utilização desta técnica devido principalmente a seu grande espectro de abrangência, uma vez que para se traçar um panorama de toda uma população, faz-se necessário uma grande amostragem de dados. Marconi \& Lakatos (2008) afirmam que uma das grandes vantagens de se utilizar uma técnica como esta está na facilidade de se obter um grande número de dados em pouco tempo, assim como seu grande alcance em termos geográficos e étnicos. Visto que o meio de divulgação é a internet, dispensa uma intervenção presencial, o que também colabora com o tempo devido a capacidade de coleta de múltiplas respostas ao mesmo tempo. 


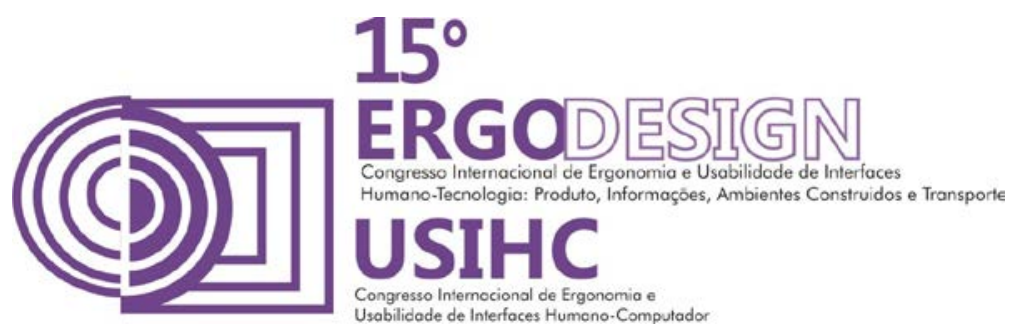

O questionário foi composto de 30 perguntas divididas em 4 seções, cada uma delas com perguntas relativas a uma questão sobre o uso de smartphones para motoristas. A primeira seção era composta basicamente por questões de filtragem de perfil de respondente, já que o escopo desta pesquisa visa apenas motoristas que utilizam smartphones durante a condução, todos aqueles que não faziam parte deste perfil de usuário foram sumariamente descartados. A segunda seção abarcou questões sobre a interação do motoristas com os seus respectivos smartphones de forma genérica: onde eles o posicionam enquanto conduz, de que forma interagem com os mesmos e afins. A terceira seção foi destinada especificamente a informações sobre a interação de motoristas com os aplicativos: que tipos utiliza, se utiliza mais de um, com que frequência utilizam, assim como as estratégias de uso. Por fim, a quarta seção possuía questões de cunho demográfico, para coletar informações sobre quem era o respondente, facilitando a caracterização dos dados e avaliar o espectro da amostragem colhida.

O questionário foi montado na plataforma de survey "Eval and Go" e divulgado em território brasileiro, com respondentes de todas as regiões do país. O principal meio de divulgação do questionário foram redes sociais, fóruns e comunidades relacionados tanto a conteúdos relativos a plataformas mobile, quanto a conteúdo automotivo. Os dados coletados nessa etapa são quantitativos e mostram quais os hábitos mais comuns entre os brasileiros.

Ao final da aplicação da técnica, foram coletadas 378 amostras completas, ou seja 378 respondentes chegaram ao final do questionário. Deste grupo, 248 pertenciam perfil de respondente procurado na pesquisa: pessoas habilitadas a conduzir que utilizam seus smartphones durante a condução (este grupo foi chamado de respondentes válidos). Dos respondentes válidos, $56 \%$ deles eram do sexo masculino e $44 \%$ feminino. Quanto a faixa etária, a maior parte deles tinham entre 18 e 50 anos e possuem smartphone a pelo menos 2 anos.

\section{RESULTADOS}

De acordo com as questões norteadoras da pesquisa, foram obtidos resultados relativos ao comportamento do motorista no trânsito. O questionário apontou que $78 \%$ dos motoristas utilizam aplicativos durante a condução. Quando observada a forma com a qual os motoristas interagem com seu smartphone durante a condução, a partir das questões relativas ao posicionamento do aparelho no automóvel, a orientação do dispositivo e o dedo utilizado para a interação, foram coletado os seguintes resultados:

- $46 \%$ das pessoas colocam seus smartphones no câmbio de marchas e 35\% no colo. (figura 6)

- Apenas $15 \%$ das pessoas colocam seus smartphones no suporte de pára-brisas, 0 que seria o mais indicado. (figura 6)

- $79 \%$ dos respondentes utilizam o smartphone na orientação vertical (modo retrato), enquanto que $21 \%$ utilizam na orientação horizontal (modo paisagem). (figura 7)

- $71 \%$ dos usuários utiliza o dedo polegar para manipular seu smartphone, seguido de $54 \%$ que utilizam o dedo indicador. (figura 8) 


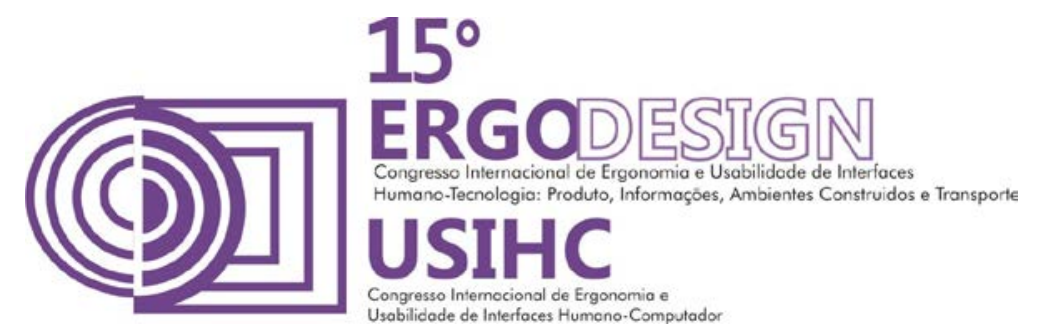

- Nenhum dos entrevistados relatou utilizar os dedos anular e mínimo. (figura 8)

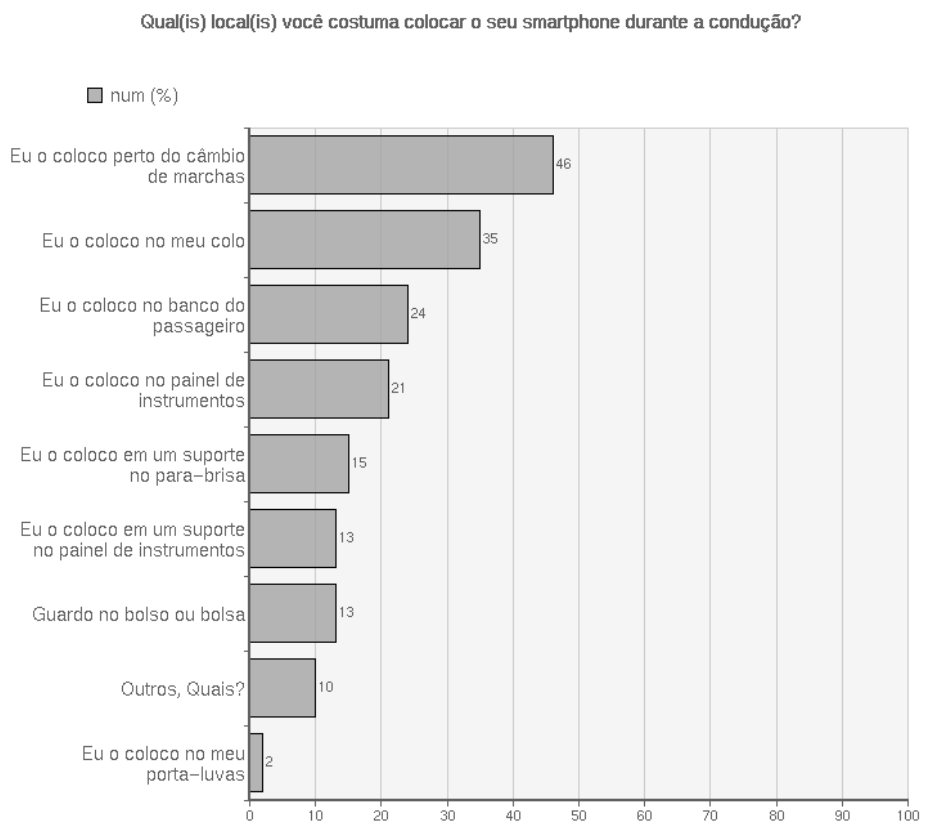

Figura 6 - Gráfico referente ao posicionamento do smartphone dentro do automóvel

Qual a orientaçẫo do seu smartphone você costuma utilizar no carro, na maioria das vezes?

$\square$ Vertical (modo retrato) (Imagem). $\quad \square$ Horizontal (modo paisagem)

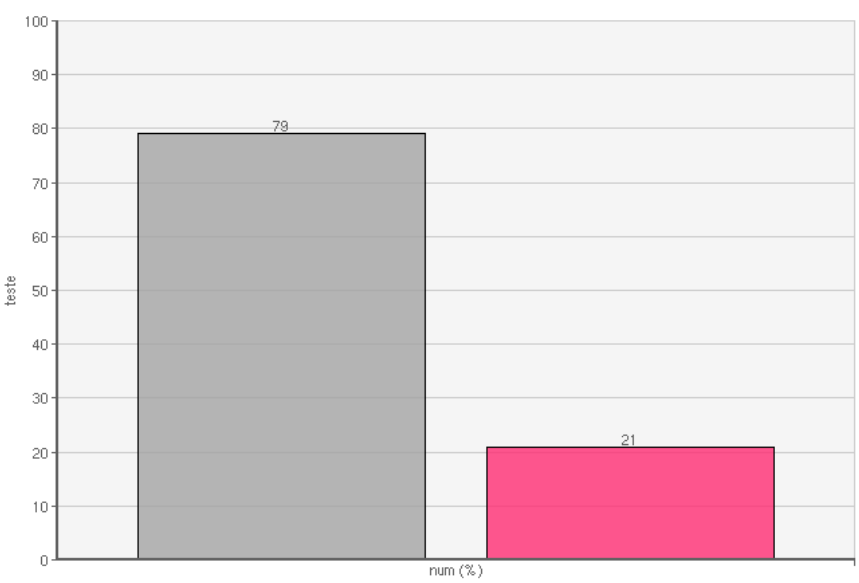

Figura 7 - Gráfico referente ao da orientação do smartphone 

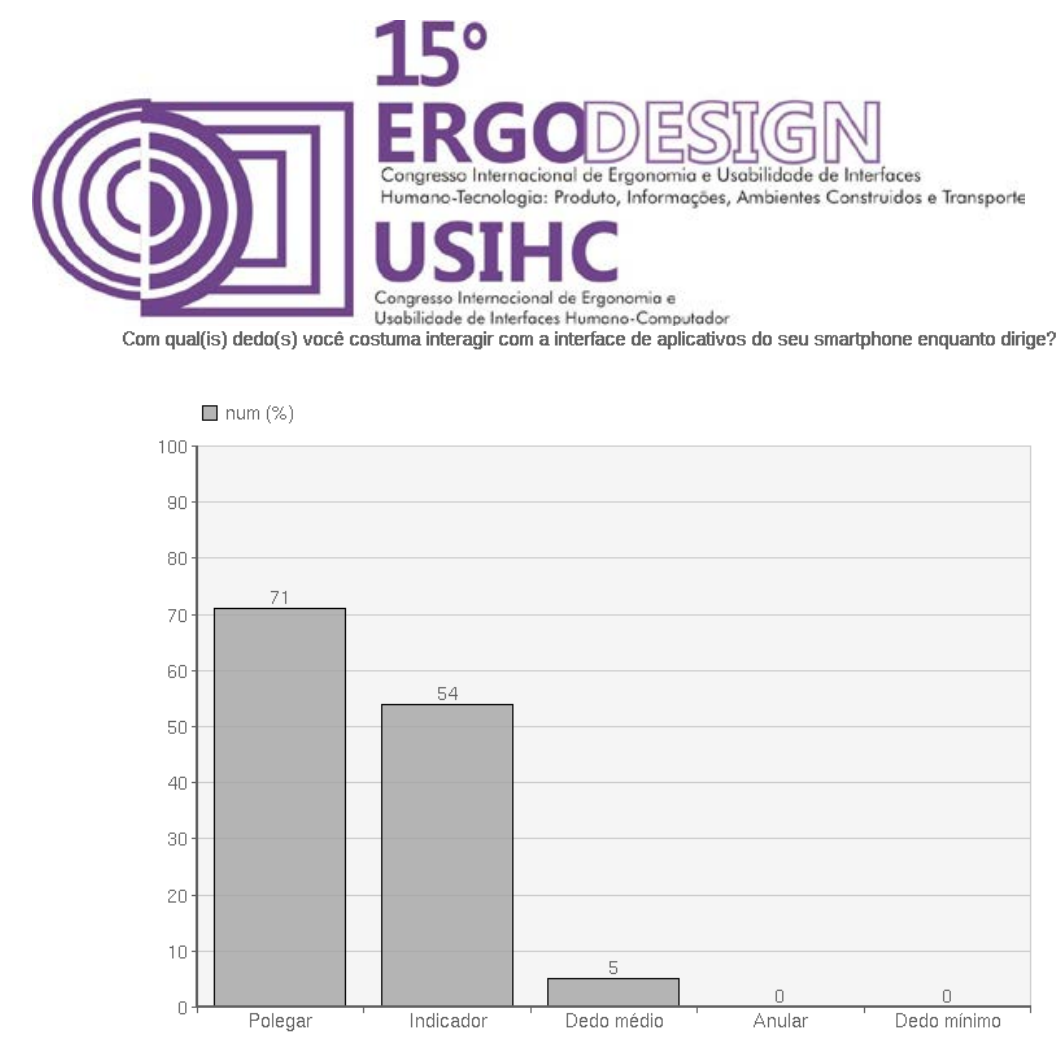

Figura 8 - Gráfico referente ao dedo utilizado para interagir com o smartphone

As questões propostas para responder quais as informações mais consultadas pelos motoristas foram "O que você consulta no seu smartphone enquanto dirige?" e "Qual(is) tipo(s) de aplicativo(s) de smartphone para motoristas você costuma utilizar?". Os resultados obtidos foram:

- As informações mais consultadas são navegação GPS e informações relacionadas ao trânsito, tráfego e trajeto. (figura 9)

- Observou-se também que $49 \%$ dos respondentes utiliza aplicativos de chat durante a condução (figura 9)

- Dentre os aplicativos mais utilizados, destacam-se as redes sociais para motorista, com $80 \%$ dos usuários. (figura 10) 

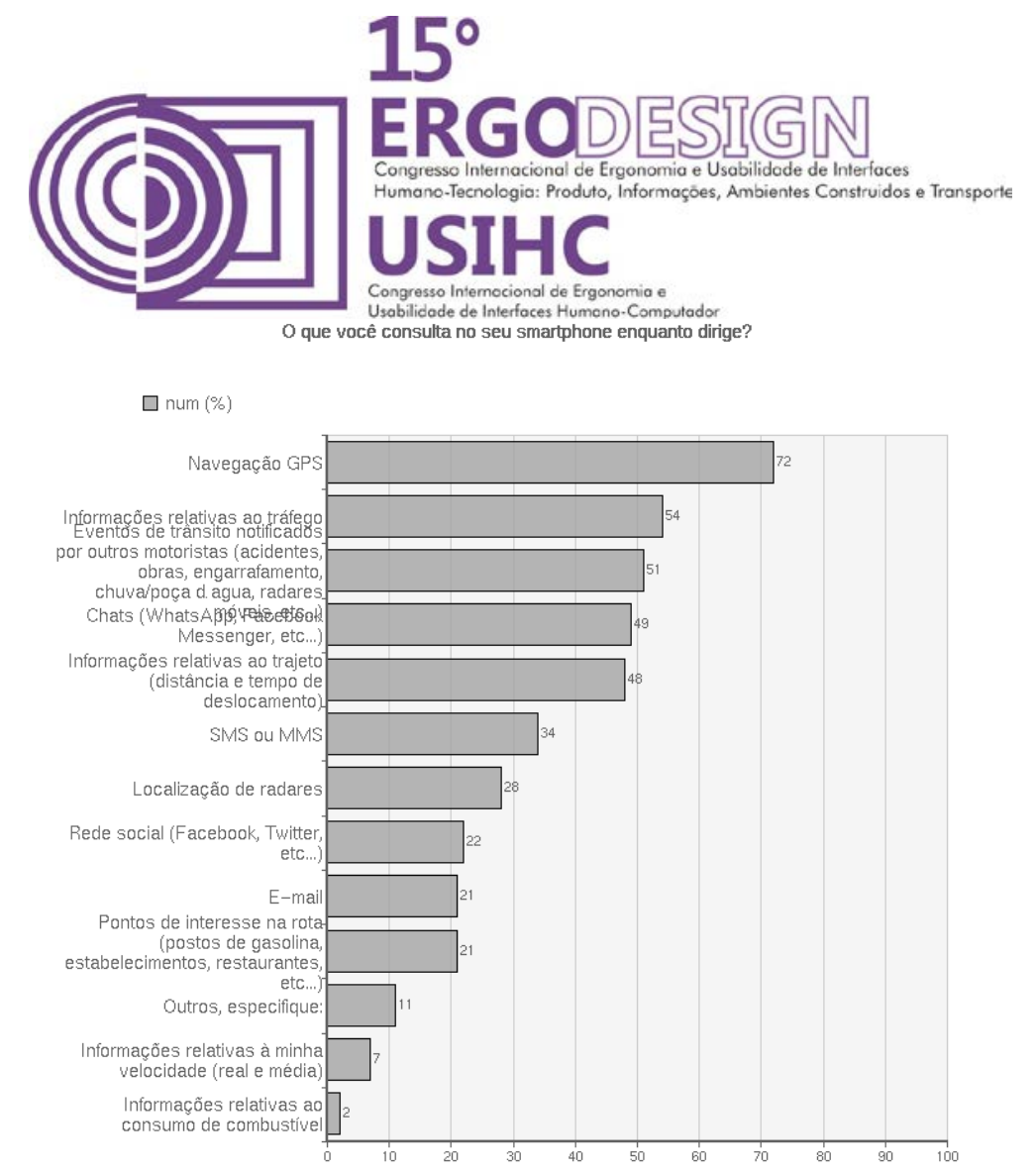

Figura 9 - Gráfico referente a consulta de informações consultadas no smartphone

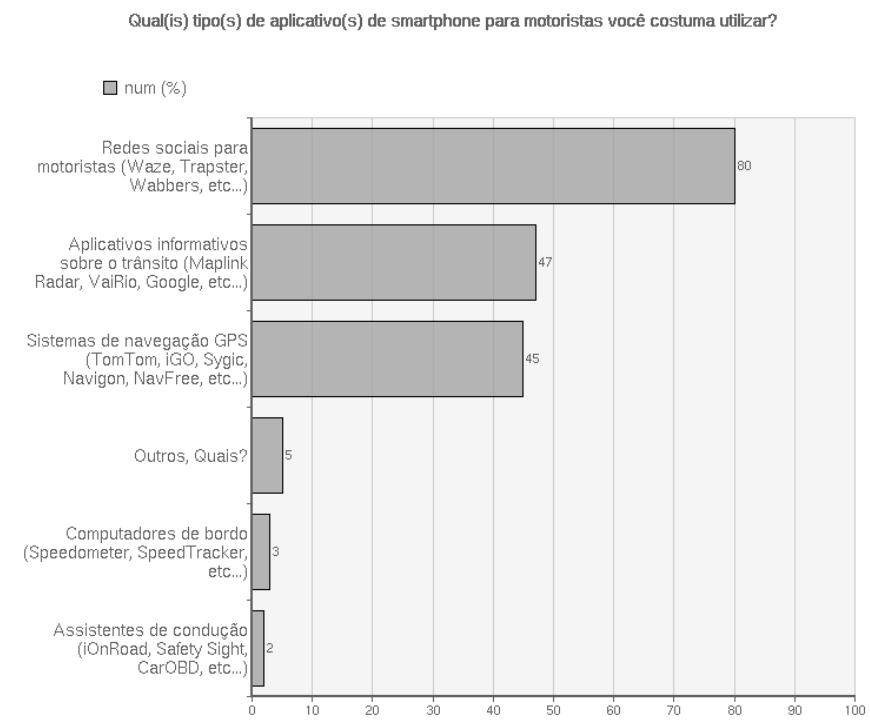

Figura 10 - Gráfico referente a questão 14 do questionário

Quanto à frequência de uso e grau de dependência do usuário quanto ao uso de smartphone durante a condução a análise foi feita a partir das questões "Com que frequência você utiliza aplicativos enquanto dirige" e "Qual o seu nível de dependência do uso de smartphone durante a condução?", cujos resultados foram: 


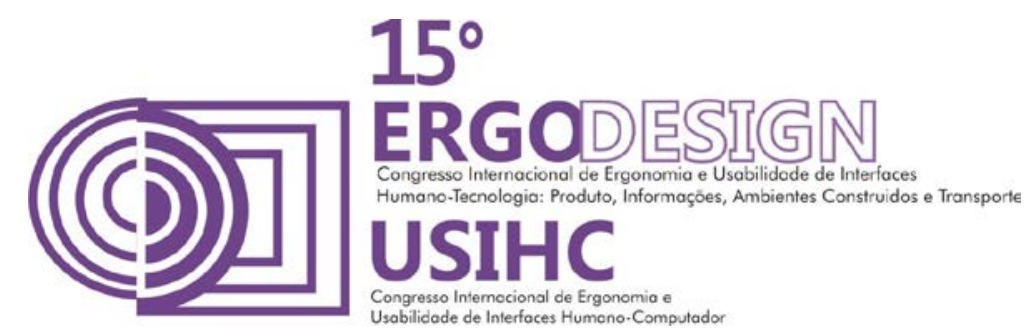

- 38\% dos respondentes alegam utilizar aplicativos durante a condução diariamente, enquanto o segundo maior grupo utiliza esporadicamente ( 2 vezes por semana), com $22 \%$ (figura 11)

- A maioria dos respondentes (54\%) alegam ter uma dependência parcial do uso de smartphones, enquanto 32\% alegaram que a utilização do celular é indiferente para eles (figura 12)

- Apenas uma pequena minoria alegou uma dependência completa ou enxergam o uso de smartphone durante a condução como uma desvantagem (figura 12)

Com que frequência você utiliza aplicativos enquanto dirige?

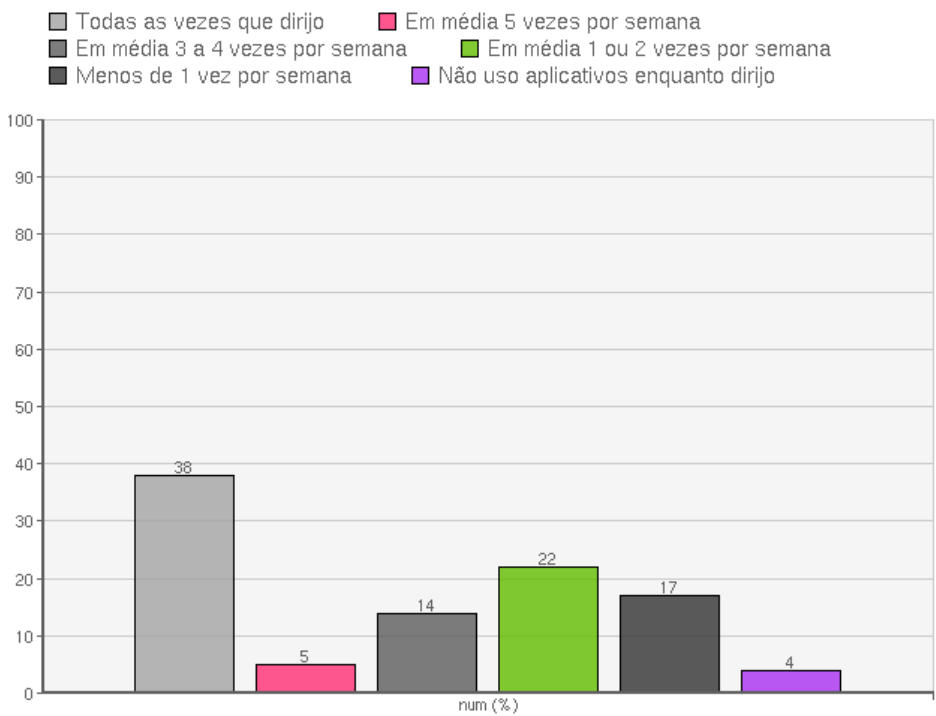

Figura 11 - Gráfico referente a frequência de uso de aplicativos enquanto dirige 

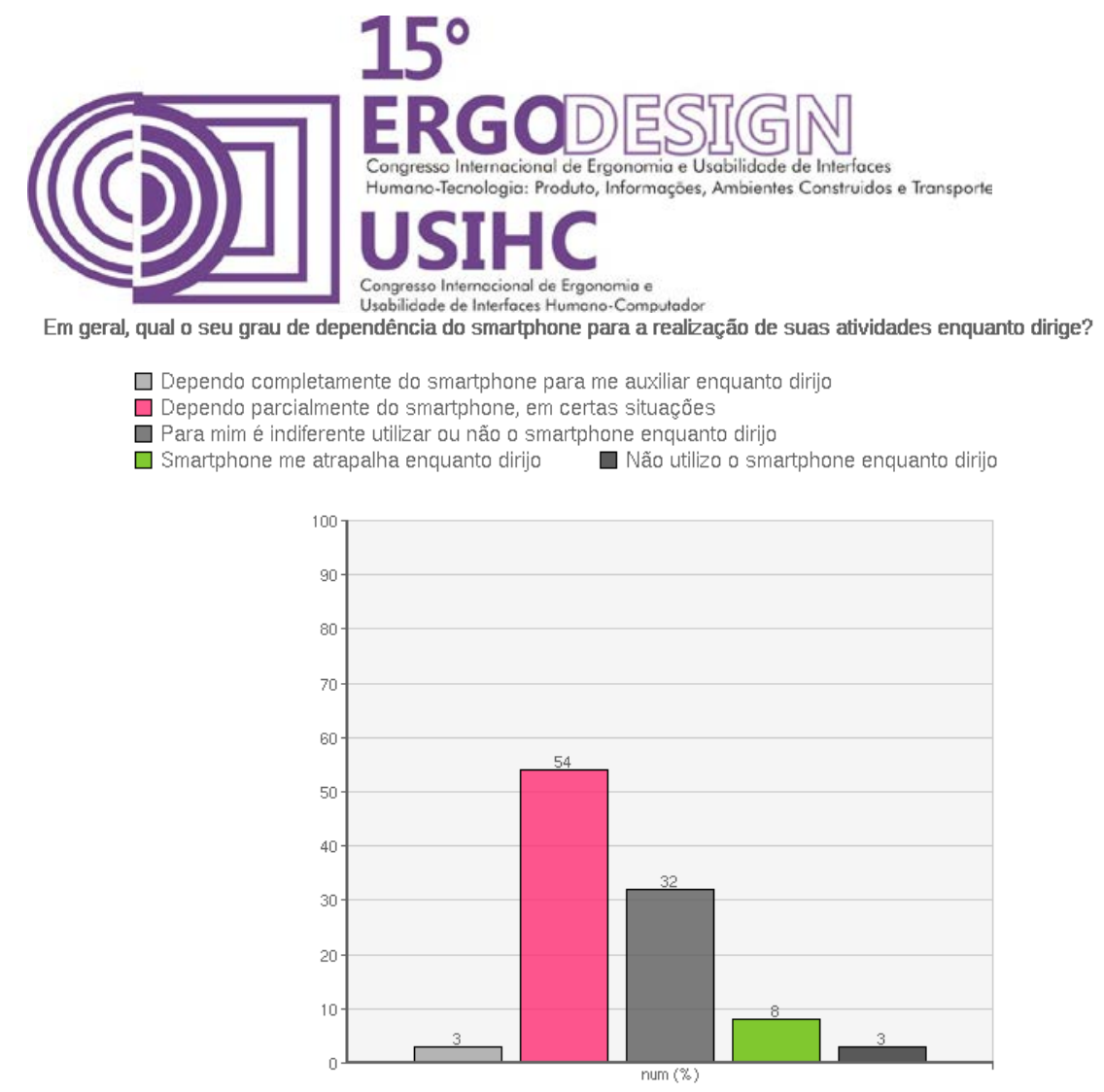

Figura 12 - Gráfico referente ao grau de dependência do smartphone para atividades enquanto dirige

A partir da pergunta aberta "Qual é a sua opinião sobre a praticidade e facilidade de uso dos atuais aplicativos para motoristas (para uso enquanto dirige)?" foi feita uma triagem e análise do conteúdo onde observou-se que $44 \%$ dos usuários estão insatisfeitos com os aplicativos existentes para motoristas, 33\% mostraram-se satisfeitos e $26 \%$ mantiveram uma posição de neutralidade quanto ao assunto. As maiores reclamações foram:

- Distração do motorista

- Difícil navegação

- Necessidade da conexão de internet

- Falta de um mecanismo de interação por voz eficiente

As melhores vantagens destacadas foram:

- A possibilidade de achar caminhos desconhecidos

- Notificações sobre o trânsito

- Praticidade e facilitação nas tarefas durante a condução

\section{CONCLUSÃO}

Este estudo foi realizado a partir de uma enquete online sobre o uso de smartphones por motoristas durante a condução. O objetivo do estudo foi analisar e montar um panorama geral sobre a opinião, comportamento e estratégia de uso de seus aparelhos celulares enquanto dirigem. Os resultados encontrados apontam para uma série de comportamentos tanto de uso do smartphone em si quanto ao uso dos aplicativos que rodam nos mesmos. 


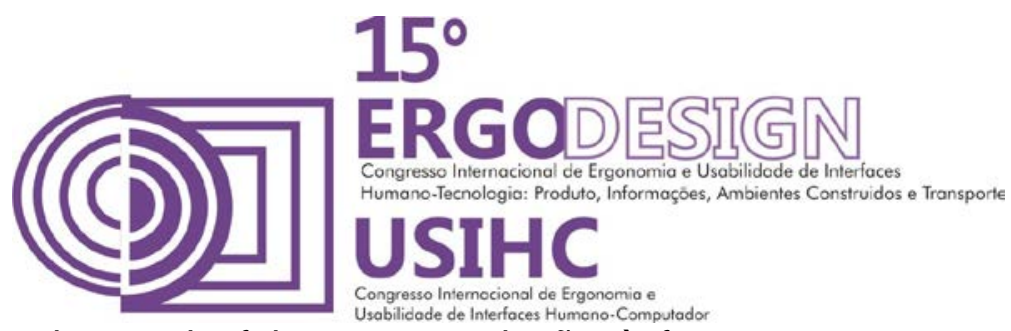

O primeiro ponto observado foi que em relação à forma com que as pessoas utilizam diretamente os celulares enquanto dirigem. A maior parte delas posiciona seus aparelhos em seu colo, ou no console, próximo ao cambio de marchas. Isso justifica a utilização dos aplicativos em modo retrato (verticalizado) e a interação com o polegar, uma vez que necessitam segurar o aparelho na mão para interagir com a interface dos aplicativos, dada a falta de um suporte adequado.

Quanto ao uso de aplicativos em si, o tipo de informação mais procurada foram principalmente relativas a trânsito ou questões de conforto, para evitar engarrafamentos, blitz e etc... Também foi constatado um grande percentual de uso de aplicativos de chat durante a condução, o que mostra também a questão da busca do conforto e praticidade no uso de aplicativos e a necessidade de estar conectado com outras pessoas e/ou otimização no tempo gasto em trânsito.

Em geral, pode-se constatar que os resultados do questionário apontam para um comportamento pouco preocupado com questões relativas à segurança durante a condução. Este comportamento pode ser observado em afirmativas diversas ao longo da enquete, como por exemplo a baixa frequência do uso de um suporte adequado para 0 aparelho, o que faz com que os motoristas tenham que desviar o olhar completamente da via e retirar suas mão do volante por um longo tempo em troca de uma praticidade maior no uso dos aplicativos. Outro exemplo de um comportamento despreocupado com questões relativas à segurança está na forte presença do uso de chats de texto durante a condução, o que é um problema fortemente combatido por instituições internacionais como a NHTSA. Em suma, pode-se observar que questões de conforto, como a praticidade na pega do aparelho, ou informações sobre como evitar engarrafamentos se sobressaem em termos de prioridade em relação a fatores cruciais para segurança, como a visão constante da via e o auxílio na condução.

Este estudo faz parte de uma pesquisa maior em desenvolvimento sobre a usabilidade de aplicativos de smartphone para motoristas, a qual tem o objetivo final de desenvolver guidelines de desenvolvimento de aplicativos melhor adaptados ao usuário e ao contexto da condução. Para os desdobramentos da pesquisa, pretende-se realizar estudos de campo com a interação direta com o usuário, selecionados de acordo com os perfis comportamentais encontrados neste estudo, para que os dados sejam validados e sirvam de insumo para a criação de diretrizes.

\section{REFERÊNCIAS BIBLIOGRÁFICAS}

CLARK, J. Tapworthy: Designing Great iPhone Apps. Sebastopol: O'Reilly Media, 2010. 322 p. ISBN 1449381650. FANGER, P. O. Thermal Comfort - Analysis and Applications in Environmental Engineering. McGraw-Hill Book Company. New York, 1972.

STATISTA. Number of available apps in the Apple App Store from july 2008 to September 2014. Disponível em: http://www.statista.com/statistics/263795/number-of-available-apps-in-the-apple-appstore/. Data de acesso: 25 de janeiro de 2015.

NHTSA. Visual-Manual NHTSA Driver Distraction Guidelines for Portable and Aftermarket Electronic Devices; A Notice by the National Highway Traffic Safety Administration on 02/12/2014. Disponível em: https://www.federalregister.gov/articles/2014/02/12/2014-03064/visual-manual-nhtsadriver-distraction-guidelines-for-portable-and-aftermarket-electronic-devices. Data de acesso: 10 de 
outubro de 2014.

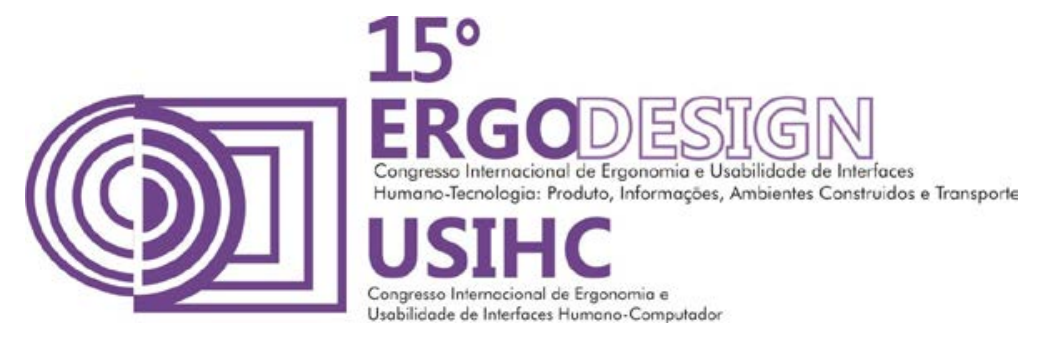

MARCONI \& LAKATOS. Técnicas de Pesquisa. Editora Atlas. 2008. São Paulo, SP

National Highway Traffic Safety Administration. Visual-Manual NHTSA Driver Distraction Guidelines for InVehicle Electronic Devices. Vol. 79 No. 179, 2014.

QUARESMA, Manuela . Assessment of visual demand of typical data entry tasks in automotive navigation systems for iPhone. Work (Reading, MA), v. 41, p. 6139-6144, 2012.

QUARESMA, Manuela; GONCALVES, R. C. . Análise da usabilidade de aplicativos rede social para motoristas. Arcos Design (Online), v. 7, p. 25-52, 2013.

QUARESMA, Manuela ; GONCALVES, R. C. . Usability Analysis of Smartphone Applications for Drivers. Lecture Notes in Computer Science, v. 1, p. 352-362, 2014.

WROBLEWSKI, L. Mobile First. New York: A Book Apart, 2011. 123 p. ISBN 1937557022. 